\title{
On the nature of crosslinks in thermoreversible gels
}

\author{
Klaas te Nijenhuis \\ Laboratory of Polymer Materials and Polymer Engineering, Faculty of Applied Sciences, Delft \\ University of Technology, Julianalaan 136, NL 2628 BL Delft, The Netherlands \\ E-mail: k.tenijenhuis@tnw.tudelft.nl
}

Received: 6 July 2005 / Revised version: 19 December 2005 / Accepted: 21 December 2005

Published online: 19 June 2006 - (C) Springer-Verlag 2006

\section{Summary}

A review is given concerning the nature of crosslinks in thermoreversible gels. In these gels the crosslinks can be formed e.g. by means of crystallisation of parts of polymer molecules, by liquid-liquid phase separation in solution and in bulk, by hydrogen bridging, by complexation of polymer chains, by helix formation, by chemical equilibrium reaction or by interactions between side-chains. One example will be given for each of these eight possibilities of crosslink formation.

\section{Introduction}

In classifying networks Flory [1] proposed to subdivide them into four types:

1. Well-ordered lamellar structures, including mesophases;

2. covalent polymer networks, completely disordered;

3. networks formed through physical aggregation, predominantly disordered, but with regions of local order;

4. particulate, disordered structures.

Examples of the first type are soap gels, phospholipids and clays; electrostatic and/or Van der Waals forces play a predominant role in the gel formation. The second category of gels consists of the well-known chemical networks, formed by crosslinking of high molecular weight polymers or by crosslinking reactions in polymerisation or polycondensation processes. To the third type belong many polymers and biopolymers, where only relatively small parts of the polymer chains are involved in some physical interaction like e.g. crystallisation, helix formation and complex formation. The fourth class of gels includes flocculation precipitates, which usually consist of particles of large geometric anisotropy (needles or fibrils). It is generally accepted that many thermoreversible gels belong to the third type of gels in Flory's classification. Schematic views of the various kinds of thermoreversible gels are shown in Fig.1. However, if the crosslinks are involved in a chemical equilibrium process, the amount of crosslinks will be temperature dependent and the gels formed will be also thermoreversible.

Presented at $44^{\text {th }}$ P.M.M. Microsymposium "Polymer Gels and Networks", Prague, 10-14 July 2005 


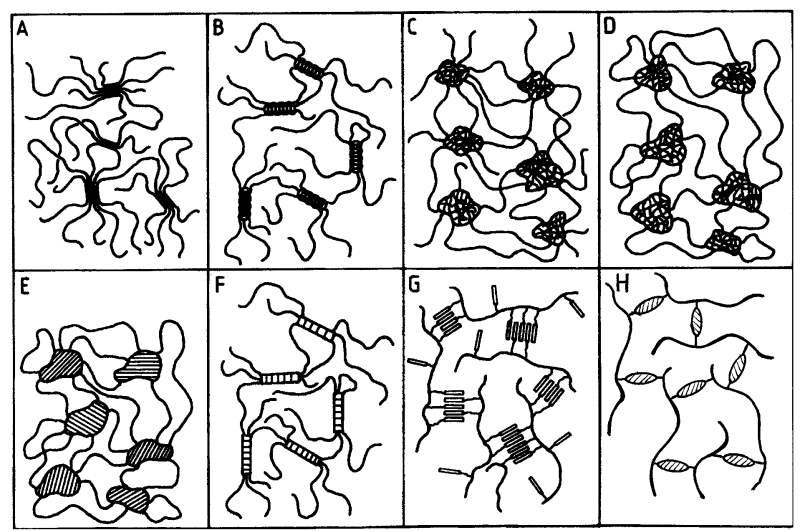

Figure 1. Schematic view of various kinds of thermoreversible gels: A PVC/plasticizer; B aqueous gelatin; $\mathbf{C}$ atactic $\mathrm{PS}$ in $\mathrm{CS}_{2} ; \mathbf{D}$ triblock copolymer SBS in tetradecane; $\mathbf{E}$ PO-EO-PO triblock copolymer in water (semicrystalline EO blocks); F s-PMMA and i-PMMA in toluene; $\mathbf{G}$ dissolved SCLCP; $\mathbf{H}$ chemical equilibrium in HPAAm-chromium (III).

Several reviews concerning thermoreversible gels have been produced in the recent past [2-4], but no review has been published concerning the structure of the crosslinks in thermoreversible gels. The present paper deals with a classification of crosslink structures of thermoreversible gels. It will be clear that this cannot be a profuse description of this kind of crosslinks.

\section{Classification of formation of crosslink structure in thermoreversible gels}

The following classification of thermoreversible gels, although not profuse, can be given on the basis of their crosslink formation, with an example for each of them:

a) crystallisation: poly(vinyl chloride)

b) liquid-liquid phase separation in solution: atactic polystyrene

c) liquid-liquid phase separation in bulk: styrene-isoprene-styrene triblock copolymers

d) complex formation: isotactic and syndiotactic poly(methyl methacrylate)

e) helix formation: Gelatin

f) hydrogen bonding: poly(vinyl alcohol) + Congo Red

g) chemical equilibrium: poly(vinyl alcohol) + borate, partly hydrolysed poly (acrylamide $)+\mathrm{Cr}^{3+}$

h) interaction of side-chains in side-chain liquid crystalline polymers: polyacrylates with discotic side-chains.

In this paper examples will be given for each of these crosslinking possibilities.

\section{Examples}

a) Crystallisation

One of the famous examples of thermoreversible gels is the gelation of moderately concentrated poly(vinyl chloride) solutions. An example is given in Fig.2, where the 
storage modulus of a $10 \%$ solution of PVC in dioctyl phthalate (DOP) is plotted vs. angular frequency on double logarithmic scales for various ageing times after cooling down the solution from $160^{\circ} \mathrm{C}$ to $90^{\circ} \mathrm{C}$ [4-7].

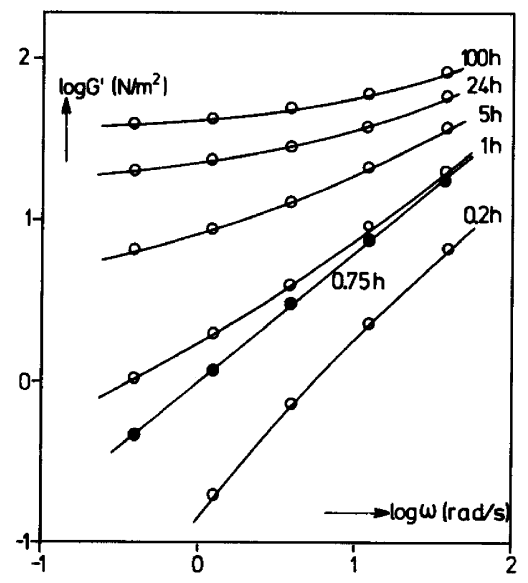

Figure 2. Storage modulus of $10 \%$ PVC/DOP plotted vs. angular frequency for several ageing times; ageing temperature $90^{\circ} \mathrm{C}$. Reproduced from Physical Networks, Polymers and Gels [5] by the courtesy of Chapman \& Hall.

The gradual formation of a network is shown. According to the Winter-Chambon method the critical ageing time is $0.75 \mathrm{~h}$ [8]. This behaviour is in general shown for the development of physical and chemical networks. That the crosslinks in PVC gels are tiny crystallites was proven with the aid of X-ray diffraction [9-12] and by model calculations [13-15]. In the work of Dorrestijn et al. [16] the ageing process of $10 \%$ PVC-gels was followed with dynamical analysis as well as with small angle X-ray scattering. A secondary maximum in the scattering curve was observed at a scattering angle that appeared to be independent of the amount of ageing. From this scattering angle, the authors calculated with the aid of Bragg's law for the PVC/DOP system a long distance of $30 \mathrm{~nm}$. This distance was considered to be the average mutual distance between the crystalline crosslinks. The present author $[4,17,18]$ calculated the number of polymer molecules that are incorporated in such microcrystallites and thus the functionality ${ }^{1}$ of the crosslink (i.e. twice that number). Results are shown in Fig.3, where both the storage plateau modulus and the average crosslink functionality are plotted vs. log ageing time. It demonstrates that during the increase of $G_{\mathrm{e}}$ from 600 to $2800 \mathrm{~N} / \mathrm{m}^{2}$, i.e. during approximately 3 weeks of ageing at $28{ }^{\circ} \mathrm{C}$, the average functionality increases from 16 to 36 . This means that 8 to 18 polymer molecules are involved in the microcrystalline crosslinks. The conclusions are a) that the crystallites are created in the very beginning of the ageing process, b) that no new crystallites are formed and c) that during the ageing process the size of the crystallites increases, because more and more polymer molecules are incorporated in the microcrystallites. As a result the functionality of the crosslinks increases during ageing.

\footnotetext{
${ }^{1}$ Functionality of a crosslink is defined here as the number of polymeric chains that leave the crosslink
} 


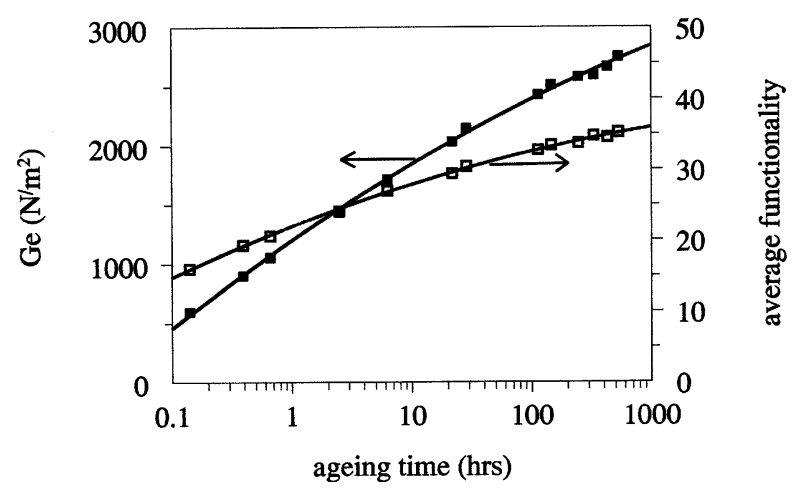

Figure 3. Plateau storage modulus (left) and average crosslink functionality (right) vs. ageing time for $10 \mathrm{wt} \%$ PVC gels in dioctyl phthalate at $28^{\circ} \mathrm{C}$.

\section{b) Liquid-liquid phase separation in solution}

When a solution of high molecular weight polystyrene in carbon disulfide, $\mathrm{CS}_{2}$, is quenched to low temperatures, gelation will occur, due to liquid-liquid phase separation. Clark et al. [19] showed this by quenching a $9.5 \%$ solution of atactic Polystyrene $\left(M_{\mathrm{w}}=900 \mathrm{~kg} / \mathrm{mol}\right)$ to temperatures varying from $-10^{\circ} \mathrm{C}$ to $-22{ }^{\circ} \mathrm{C}$. They measured the storage modulus as a function of frequency and their results are similar to those shown in Fig. 2 for $10 \%$ PVC/DOP, but now the temperature is the parameter at the different curves. For this system the Winter-Chambon method yields a maximum gelation temperature of $-14^{\circ} \mathrm{C}$. Hence, gelation is only possible below this temperature. Berghmans et al. [20-23] proved that phase separation plays a predominant role in the gelation process of this kind of systems. Phase separation is schematically illustrated in Fig.4 [4]. Upon cooling a dilute solution (point A), phase separation will occur when point $C$ is reached and two phases will develop: $C_{1}$, the polymer poor phase, and $\mathrm{C}_{2}$, the polymer rich phase. However, two clearly distinct phases will not be created: a dispersion of polymer rich micro-droplets develops in a polymer poor liquid phase and parts of the long polymer molecules will be incorporated in different droplets. Coalescence of the droplets is prevented because a network will be formed consisting of polymer molecules that connect the polymer rich droplets. If the temperature is low enough, i.e. below the glass transition temperature of the polymer rich phase, then a network with almost infinite relaxation times will be formed. If the temperature is higher than the glass transition temperature, then a temporary network will be formed. In Fig.4 the broken line indicates the concentration dependence of $T_{\mathrm{g}}$ if no phase separation would occur. However, the $T_{\mathrm{g}}-\varphi$ curve crosses the bimodal curve at $\mathrm{D}_{2}$, i.e. the so-called Berghmans point. From that point on the $T_{\mathrm{g}}$ curve becomes rather flat and in the case of a monodisperse polymer even horizontal [24]. Upon cooling a solution from point A to D, polymer rich droplets in their glassy state are obtained .

According to Keller et al. [25] various classes of gels will be formed depending on the concentration. They are schematically shown in Fig.5: molecularly connected, in general obtained in low concentrated solutions; phase connected (continuous) in general obtained in solutions with concentrations around the maximum in the phase diagram and phase connected (adhesive), in general obtained in concentrated solutions, but of course within the bimodal region. 


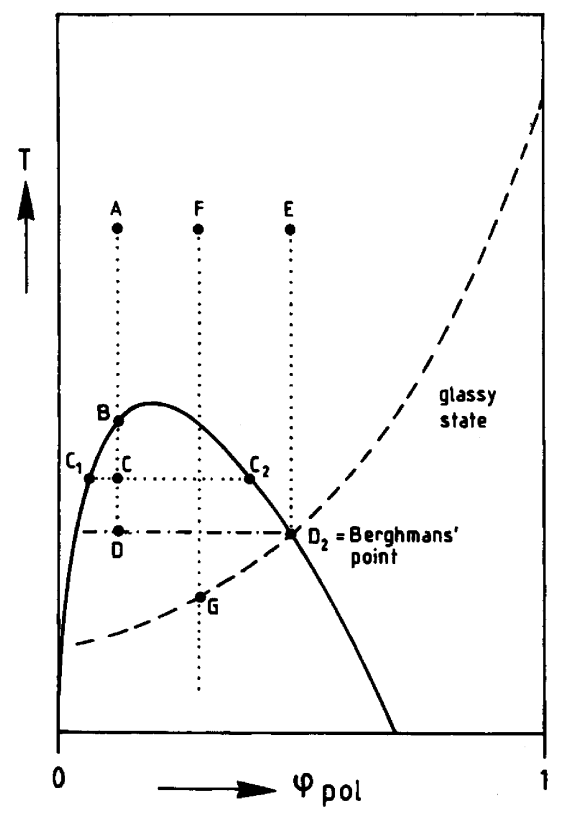

Figure 4. Phase diagram, shown

schematically, of solutions of monodisperse polymer for which the glass transition curve (----) crosses the bimodal curve.

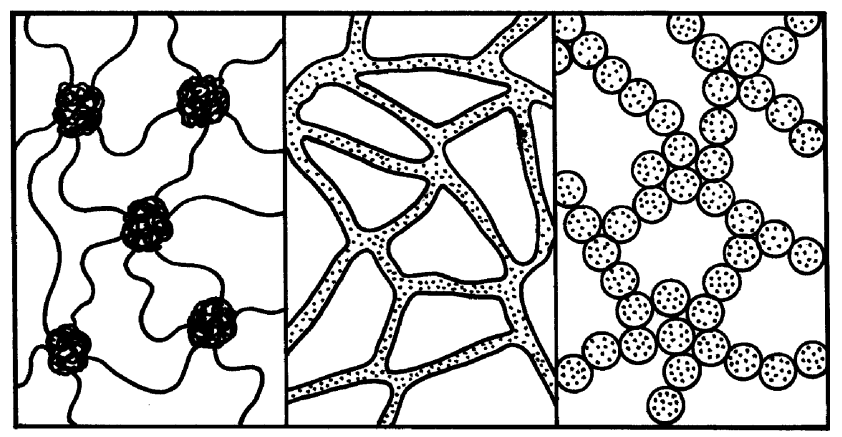

Figure 5. Schematic illustration of the three classes of gels: left: molecularly connected; centre: phase connected (continuous); right: phase connected (adhesive). Reproduced from Makromol Chem [25] by the courtesy of Hüthig \& Wepf Verlag Publishers, Switzerland.

\section{c) Liquid-liquid phase separation in bulk}

Upon dissolving a triblock copolymer ABA in a selective solvent, which is a solvent for polymer B and a precipitant for polymer A, the A blocks will have the tendency to associate in swollen domains. In dilute solutions a micellar structure is formed, while in concentrated solutions more or less rigid organised structures can be formed (cylinders or lamellae). The A-blocks are best incorporated in different domains, because in that case the entropy of the B-blocks are not lowered too much, as would be the case when forming a loop, by back folding to the same domain [26]. In this way a three dimensional network will be formed: the A-block domains behave as multifunctional crosslinks and the flexible B-blocks as network chains. According to Mortensen et al. [27] unimers are present at very low concentration, a random network at low concentrations and a micellar network (see Fig.6) at high concentrations. 


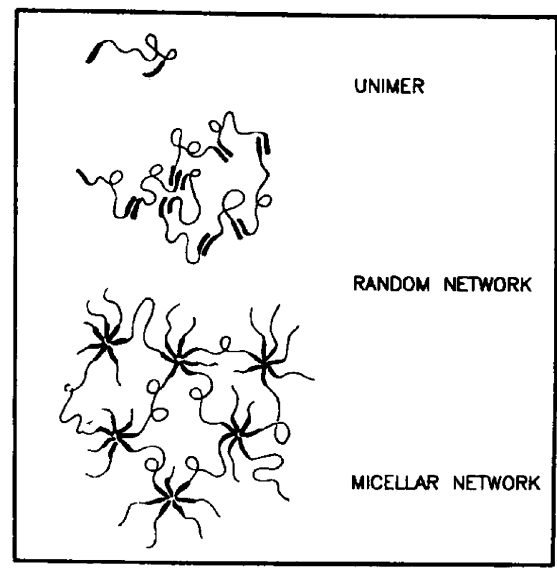

Figure 6. Schematic representation of different phases in triblock copolymer solutions; unimers and two structures leading to networks: random network and micellar network. Reproduced from Macromolecules [27] by the courtesy of The American Chemical Society.

The permanence of networks of triblock copolymers depends on the dynamics of the equilibrium between the aggregates or micelles and unimers. If the dynamics are fast, i.e. at temperatures far above the glass transition temperature of the swollen Adomains, the system behaves like an elastic liquid. If the dynamics are slow, i.e. at temperatures close to the glass transition temperature of the swollen A-domains, a temporary network with a pseudo rubber plateau may arise. If the temperature becomes below the glass transition temperature of the swollen A-domains, the dynamics are practically absent, and a permanent network is obtained. Spitteler [28] reported measurements on SIS triblock copolymer solutions. An example of the dynamic moduli of a $1 \%$ solution of the styrene-isoprene-styrene triblock copolymer SIS-12-320-12 in $n$-tetradecane is shown in Fig.7. At temperatures of $20^{\circ} \mathrm{C}$ and higher the system behaves like an elastic liquid (low frequency slopes of 2 and 1 for $G^{\prime}$ and $G^{\prime \prime}$, respectively), but with a tendency for a rubber-like plateau at higher
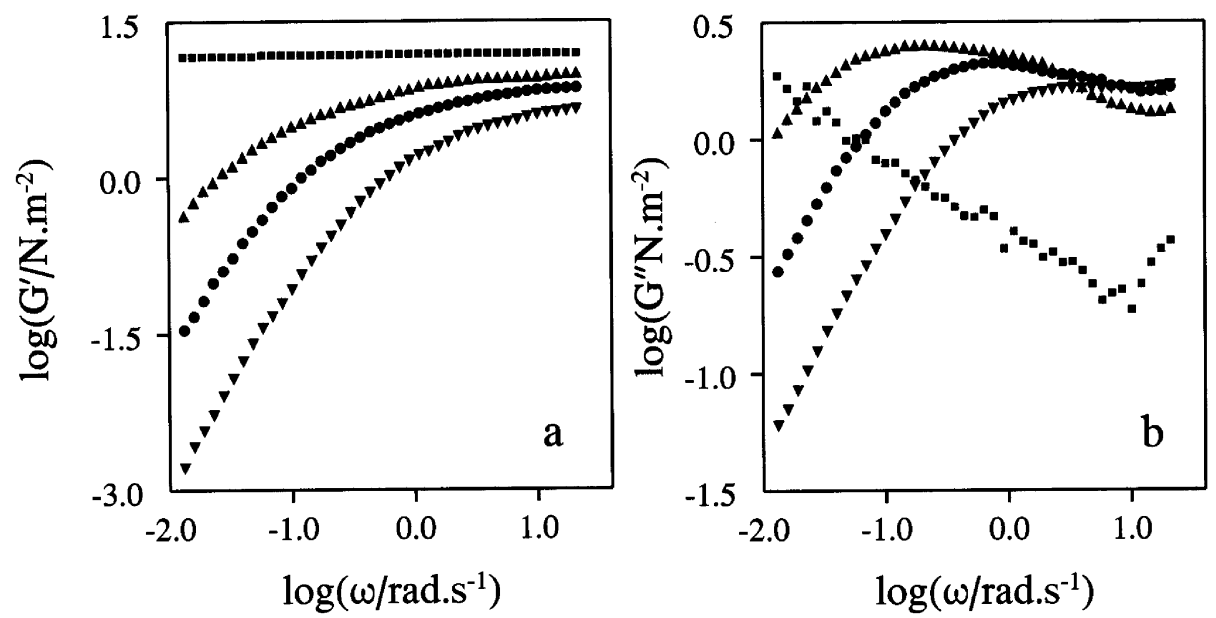

Figure 7. Dynamic moduli of $1 \mathrm{wt} \%$ SIS-12-320-12 solutions in n-tetradecane at different

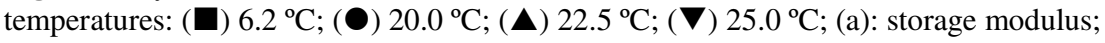
(b): loss modulus. After ref. [28]. 
frequencies. At $6.2{ }^{\circ} \mathrm{C}$ a permanent rubber network seems to exist with a slope of less than 0.01 in Fig.7a. Nevertheless the network is a temporary network, as becomes clear from the increase of the loss modulus with decreasing frequency. This means that a maximum will be present at lower frequencies. This maximum will be attended by a decrease in the storage modulus, so that relaxation will take place. Apparently, for a permanent network with infinite relaxation times, the temperature will have to be still lower, viz. below the glass transition temperature of the swollen domains.

Interesting are the time constants of these systems, i.e. the time needed for stress relaxation, due to dynamics of the aggregation equilibrium. From Spitteler's results it follows e.g. that the time constant for relaxation is approximately $1.6 \mathrm{~s}$ for the $1 \%$ solution of SIS $12-320-12$ at $25^{\circ} \mathrm{C}$. For other SIS samples with approximately the same I-block but with different S-blocks, time constants were also published: for SIS 10-330-10 and 9-330-9 they are approximately 0.4 and 0.2 s, respectively. Roughly speaking, the time constant increases logarithmically with the molecular weight of the styrene blocks.

\section{d) Complex formation}

Mixtures of solutions of isotactic and syndiotactic poly(methyl methacrylate) may give rise to gel formation. Upon mixing relatively concentrated solutions of $i$-PMMA and $s$-PMMA gel formation takes place almost instantaneously: the melting point is sharp and strongly dependent on the stereoregularity of both polymers. In many publications, the maximum effect is reported to be $i / s=1 / 2$, although also other ratios, $2 / 1$ and $1 / 1$ were found. In many cases, however, imperfect stereoregularity was the reason for these discrepancies (see e.g. ref. [4]). It seems that the complex formation starts with $i / s=1 / 1$, whereas during annealing it changes to $i / s=1 / 2$. With the aid of differential scanning calorimetry Schomaker et al. [29, 30] have shown that annealing results in a slow shift from $i / s=1 / 1$ to $1 / 2$. An example of this shift is shown in Fig.8, where, for increasing annealing time, the heat of complex formation, $\Delta H_{\mathrm{c}}$, is shown as a function of molar fraction of $s$-PMMA [30]. The maximum of the curve increases in the course of time and shifts from $i / s=1 / 1$ to $i / s=1 / 2$. For the stereocomplexation of PMMA, a minimum sequence length is required [31-36]; for most solvents 8 to 10 monomeric units are needed. Although measurement techniques can yield quite high fractions of isotactic and syndiotactic dyads, this does not always mean that all sequence lengths are long enough. Moreover, the $i / s$ ratio measured is in that case

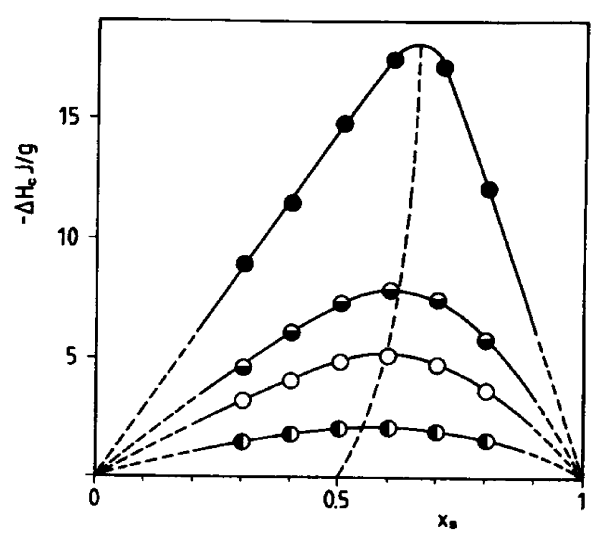

Figure 8. Heat of complexation as a function of basemole fraction $s$-PMMA, $x_{\mathrm{s}}$, evolved within from bottom to top: $100 \mathrm{~s}, 200 \mathrm{~s}, 300 \mathrm{~s}$, $1 \mathrm{~h}$ after mixing $2.5 \mathrm{~kg} / \mathrm{m}^{3} \mathrm{DMF}$ (dimethylformamide) solutions of $i$ - and $s$ PMMA at $30^{\circ} \mathrm{C}$. Reproduced with permission of the author, from ref. [30]. 
generally not equal to the $i / s$ ratio in the complex. If the concentration is high enough, then immobilisation is attended with gelation of the system. In the complex that then works as a crosslink, $i / s$ is always $1 / 1$, because in the first instance the complex is determined by the chance that two chains meet. Because of immobilization of the polymer molecules in the network, the chance that the composition of the crosslinks will change to $i / s=1 / 2$ is small.

The structure of the stereocomplex has been the subject of many studies (see e.g. ref. [4]). A two-state rotationally disordered $9 / 1$ a double helix consisting of $1 i$-unit and 2 $s$-units (see Fig.9) was suggested by Schomaker et al. [30,37,38] on the basis of fibre diffraction patterns of the stereocomplex, as a starting point for further investigations. In this respect, they also proposed a four-stranded double helix, having twofold rotation axis of symmetry, whereas also other structures have been mentioned in literature [39-41].

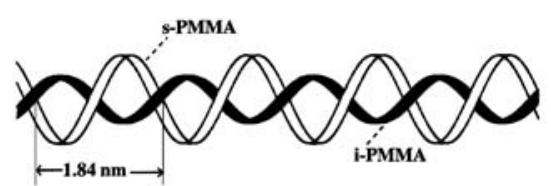

Figure 9. Top: schematic structure of the PMMA stereocomplex $(i / s=1 / 2)$; bottom: schematic representation of disorder in the structure of the stereocomplex. The bottom figure is reproduced, with permission of the author, from ref. [30].

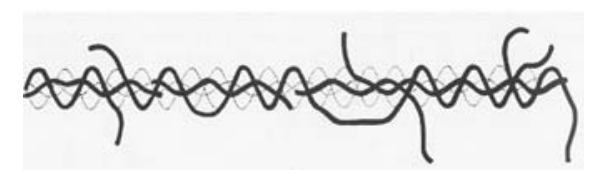

Rehage et al. [31-35] reported viscoelastic measurements on gels of mixtures of $i$ PMMA and $s$-PMMA. They made mixtures in $o$-xylene of $i$-PMMA $(93 \% i)$ and $s$ PMMA $(72 \% s)$ in a mass ratio of $4: 5$ in order to obtain an overall ratio $i / s=1 / 1$. However, it is worth mentioning that this will not be the ratio of the regular sequences that are large enough to form complexes. Solutions were made at $145{ }^{\circ} \mathrm{C}$ and subsequently cooled down to the desired ageing temperature and the ageing process was followed with time. From their results it appears that the gels are behaving like an elastic rubber with a crosslinking density strongly dependent on temperature. Apparently, temperature determines the lowest sequence length that is stable: at lower temperatures smaller sequence lengths are stable, so that more crosslinks are present. In this aspect results for solutions with different temperature histories are very interesting [44]: a solution that was preheated at $120^{\circ} \mathrm{C}$ shows a much higher tendency to form gels than a solution that was, as usual, preheated at $145^{\circ} \mathrm{C}$. This appeared from a hundredfold faster increase of the storage modulus at $120{ }^{\circ} \mathrm{C}$. Although $120{ }^{\circ} \mathrm{C}$ is well above the melting temperature of the gels, apparently complex nuclei are still present (or even complexes consisting of long sequencies), so that upon quenching to $80^{\circ} \mathrm{C}$ a very fast growth results in a fast gel formation.

\section{e) Helix formation}

In many biopolymer solutions thermoreversible gels are formed. Well-known are the gelling capacities of gelatin, agarose, carrageenans and gellan gum [2,4]. Gelatin is a polypeptide, whereas the other three biopolymers are polysaccharides. In all cases 
gel formation is the result of helix formation of parts of the macromolecules, where hydrogen bonding plays an important role. Gelation of gelatin solutions is primarily determined by the amount of the imino acids proline (PRO) and hydroxyproline (HYP), whereas also the amino acid glycine (GLY) plays an important role [42, 43]. The amount of PRO and HYP in the mother protein collagen, with a triple helix structure, and the denaturation or shrinkage temperature are strongly dependent of its source, as shown in Table 1. These data show that the stability of the structure of collagen is dependent on the imino acid content.

Table 1. Number of imino acid residues (PRO + HYP) per 1000 total residues and approximate shrinkage temperature of skin collagen of various animals [42].

\begin{tabular}{lllll}
\hline Rabbit & Crocodile & $\begin{array}{l}\text { African } \\
\text { Lungfish }\end{array}$ & Pike & Cod \\
\hline 237 & 221 & 207 & 199 & 155 \\
$41^{\circ} \mathrm{C}$ & $35^{\circ} \mathrm{C}$ & $33^{\circ} \mathrm{C}$ & $31^{\circ} \mathrm{C}$ & $20^{\circ} \mathrm{C}$ \\
\hline
\end{tabular}

Upon denaturation of collagen, the triple helix is separated into three gelatin molecules:

$$
\text { triple-helical collagen } \rightleftarrows 3 \text { random coils of gelatin }
$$

In aqueous solution the gelatin molecules are in their coiled state at temperatures above the denaturation temperature. Upon cooling well below this temperature a reversible coil-helix transition takes place. However, only relatively small parts of the gelatin molecules are able to retain the collagen structure, so that a small number of small triple helices are formed. The result is the formation of a three-dimensional network if the concentration is high enough, e.g. above $2 \%$, with triple helical crosslinks, hence with a functionality equal to 6 . The network formation is very fast: for a $2 \%$ aqueous gelatin $\left(M_{w}=70 \mathrm{~kg} / \mathrm{mol}\right)$ a rubber plateau is already present after 6 min $[4,7,44]$. The plateau modulus increases fast in the course of time and the network seems quite permanent. However, it has been reported by the present author [4] that after $45 \mathrm{~h}$ of ageing a $2 \%$ solution at $2.6^{\circ} \mathrm{C}$ a minimum in the loss modulus is present around $\omega=0.01 \mathrm{rad} / \mathrm{s}$. This means that at still lower frequencies a maximum must be present, attended with a decrease in the storage modulus: relaxation takes place (just as in the SIS triblock copolymers in tetradecane, mentioned above). Hence, the crosslinks in gelatin are not really permanent. These results are in agreement with creep measurements [45-47] and we can conclude that there seems to be some slippage in the crosslinks. Such a minimum in the loss modulus is often shown for physical gels [4] due to slippage in the crosslinks or to equilibrium processes the crosslinks are involved in. In other words, in many cases the networks are not permanent but temporary only.

Because of the BSE disease that cows suffer on, this source for gelatin is suspect nowadays. For that reason there is real interest in finding substitutes and one possible is fish collagen. However, as has been mentioned before, the PRO-HYP content of 
fish is much smaller and consequently the denaturation temperature is lower and thus the maximum temperature of gelation is lower. Moreover the gel stiffness is in general much lower. This was demonstrated by Gilsenan and Ross-Murphy, who reported dynamic mechanical measurements on solutions of bovine and cod gelatin [48]. From this work it became clear that the plateau moduli of a $30 \%$ cod solution at $2{ }^{\circ} \mathrm{C}$ and of an $8 \%$ bovine solution at $8{ }^{\circ} \mathrm{C}$ were approximately equal (see also ref. [49]. This clearly shows that substitution of mammalian gelatin by fish gelatin is quite problematic.

\section{f) Hydrogen bonding}

A famous example of crosslinking by hydrogen bonding is the gelation process of aqueous solutions of poly(vinyl alcohol) in the presence of Congo Red, where two azo and two amino groups are capable of hydrogen bonding. In this way complexation might lead to so-called weak and strong crosslinks, as shown in Figs.10a and 10b [50], where in both cases the crosslink functionality is equal to 4 , i.e. the number of polymer chains leaving the crosslink.

However, in principle it is possible that every hydrogen bond combines two polymer molecules and as a result the crosslink functionality might be 8 and in general a number between 4 and 8 . From experimental thermodynamic investigations, Beltman and Lyklema [51,52] came to the conclusion that the average functionality of PVA - congo red gels is $7.4 \pm 0.6$. From their presented dynamic mechanical

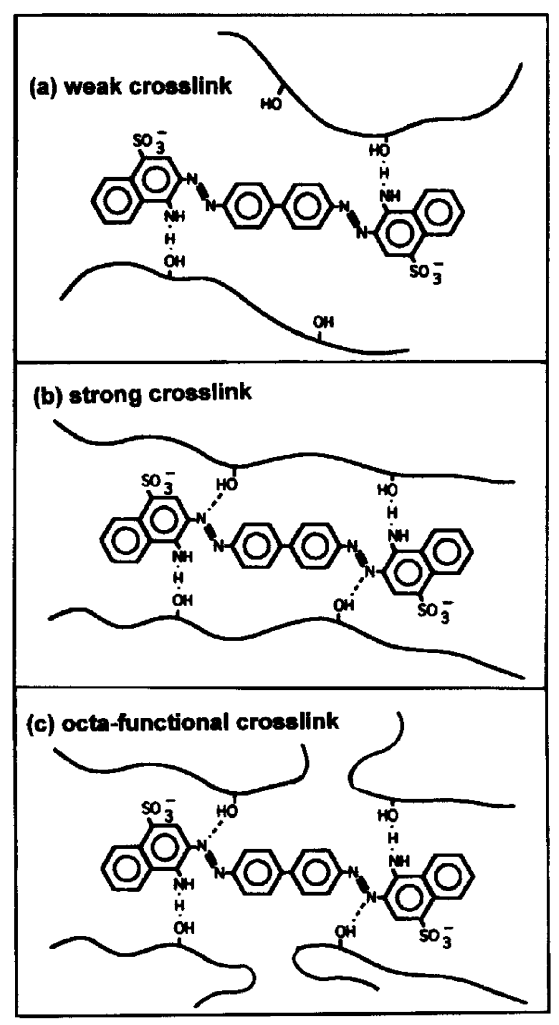

Figure 10. Schematic representation of the weak (a) and strong (b) crosslink structures in poly(vinyl alcohol) - Congo Red complexes, according to Shibayama [50] and (c) of an octafunctional crosslink, according to Te Nijenhuis $[4,18]$. 
measurements the present author was able to calculate the functionality of the crosslinks to be $7.6 \pm 0.4$, which is in agreement with the thermodynamic results $[4,18]$. These results show that the congo red molecule is able to hydrogen bonding with $\mathrm{OH}$ groups of different PVA molecules, as shown in Fig.10c.

\section{g) Chemical equilibrium}

\section{Poly(vinyl alcohol) + borate}

Aqueous poly(vinyl alcohol) solutions can be brought to gelation by e.g. borate, titanate and chromic anions. [53-56]. Already in 1949, Deuel and Neukom [54] suggested that complexation is the origin of the crosslinks in PVA borate solutions, as shown in Fig.11. In the Shibayama model [57], also shown in Fig.11, also sodium ions are needed in the process. This is in agreement with Cheng and Rodriguez [58] who demonstrated that the addition of boric acid without sodium anions to aqueous PVA solutions has almost no effect on the gelation properties. Addition of sodium hydroxide results in rapid gel formation, with an optimum for $\left[\mathrm{Na}^{+}\right] /[\mathrm{B}]=1$. Hence, crosslinking is the result of the equilibrium:

$$
\text { PVA }+ \text { borate } \rightleftarrows \text { crosslink complex }
$$

Measurements by Beltman [51] demonstrate first that the viscoelastic properties of those gels are strongly dependent on temperature and secondly that the PVA/borate gels are temporary networks, with terminal relaxation times varying from 0.02 to $2 \mathrm{~s}$ and storage plateau moduli, $G_{\mathrm{e}}$, varying from 1000 to $4500 \mathrm{~N} / \mathrm{m}^{2}$ in the temperature range from $75^{\circ} \mathrm{C}$ to $15^{\circ} \mathrm{C}$. From the height of the rubber plateau of results presented by Beltman [51], by Schultz and Myers [59] and by Koike et al. [60], the present author $[4,18]$ has calculated the crosslinking enthalpy $\Delta H^{\circ}$ to be $-11.3 \pm 0.7 \mathrm{~kJ} / \mathrm{mol}$, which is quite in agreement with Cheng and Rodrigues [58] who reported a value of $10.9 \mathrm{~kJ} / \mathrm{mol}$. Terminal relaxation times, as determined from Beltman's measurements, plotted vs. reciprocal temperature enabled the present author to calculate the heat of activation $E_{\mathrm{a}}$ to be $75 \mathrm{~kJ} / \mathrm{mol}$. This value is in agreement with the strong temperature dependence of the relaxation process. In his doctoral thesis Beltman [51] showed on photographs that at room temperature (terminal relaxation time $\approx 2.5 \mathrm{~s}$ ) cubes of gels became flat plates within half an hour.

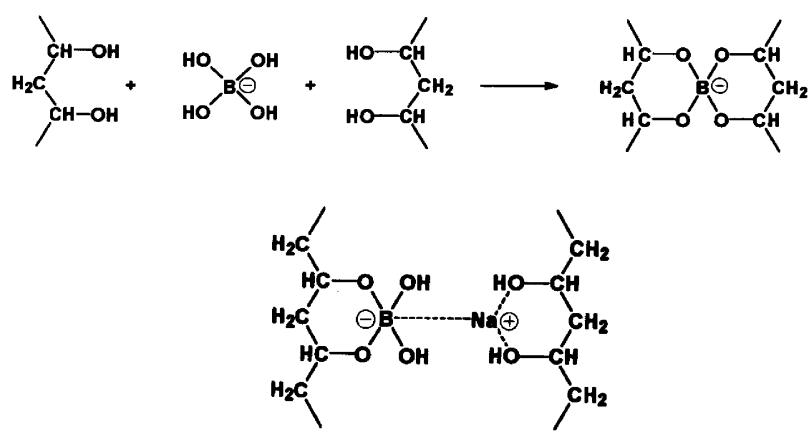

Figure 11. Structures of complex formation in aqueous poly(vinyl alcohol)-borate gels as proposed by Deuel and Neukom [54] (top) and by Shibayama et al. [57] (bottom). 
2. Partly hydrolysed poly(acrylamide) + chromium(III) ions

Partly hydrolysed poly(acrylamide), HPAAm, can be crosslinked in aqueous solution in the presence of free $\mathrm{Cr}^{3+}$ ions. For that purpose the $\mathrm{pH}$ of the solution has to be low enough, because only in that case free $\mathrm{Cr}^{3+}$ ions are present to a high enough extent. At higher $\mathrm{pH}$ protolysis of the chromium ions reduces the concentration of free $\mathrm{Cr}^{3+}$ tremendously. On the other hand at high $\mathrm{pH}$ the acid groups of HPAAm are ionised to carboxylic anions that form complexes with $\mathrm{Cr}^{3+}$. Hence, there will be only a small $\mathrm{pH}$ region were gelation is possible. An example [61] is given in Fig.12, where the storage modulus is plotted vs. angular frequency at room temperature for an aqueous $0.4 \%$ solution in brine of HPAAM ( $\overline{\mathrm{M}}_{\mathrm{w}}=10^{4} \mathrm{~kg} / \mathrm{mol}$, degree of hydrolysis $24.8 \%$ ) in the presence of $0.06 \mathrm{~kg} / \mathrm{m}^{3}$ chromium(III) and $0.01 \mathrm{~kg} / \mathrm{m}^{3}$ citric acid for $\mathrm{pH}$ varying from 2.5 to 11.6. It demonstrates that for this system networks are present in the $\mathrm{pH}$ range from 5.4 to 9.6. From a Winter Chambon plot, where $\tan \delta$ is plotted vs. pH for angular frequencies varying from 0.0628 to $6.28 \mathrm{rad} / \mathrm{s}$, it appeared that two $\mathrm{pH}$ gel points are present, which demonstrates again that under these circumstances gelation is only possible in the limited $\mathrm{pH}$ window $5<\mathrm{pH}<9$ [61].

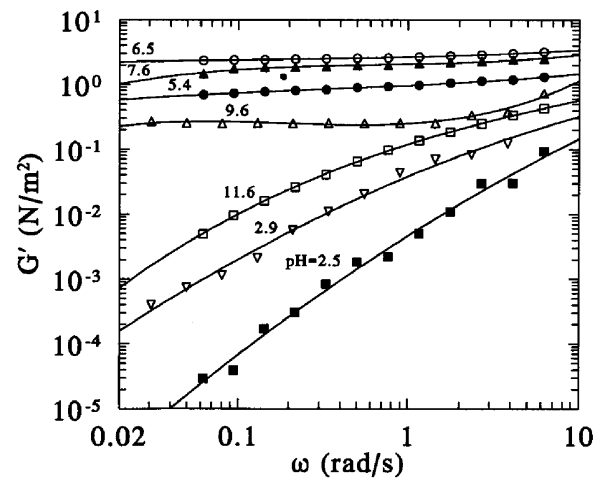

Figure 12. Double logarithmic plot of the storage modulus after $24 \mathrm{~h}$ of ageing vs. angular frequency of solutions in brine of HPAAM $\left(4 \mathrm{~kg} / \mathrm{m}^{3}\right)$, chromium(III) $(0.06$ $\left.\mathrm{kg} / \mathrm{m}^{3}\right)$ and citric acid $\left(0.01 \mathrm{~kg} / \mathrm{m}^{3}\right)$ for $\mathrm{pH}$ varying from 2.5 to 11.6. Reproduced from Rheol Acta [Ref.61] by the courtesy of Steinkopff Verlag Darmstadt, FRG.

From a detailed study of the equilibrium constant of the crosslinking process, the present author [62] came to the conclusion that the crosslinks are formed in a two-step process:

$$
\begin{aligned}
& 2 \mathrm{Cr}^{3+}+2 \mathrm{H}_{2} \mathrm{O} \rightleftarrows \mathrm{Cr}_{2}(\mathrm{OH})_{2}^{4+}+2 \mathrm{H}^{+} \\
& \mathrm{Cr}_{2}(\mathrm{OH})_{2}^{4+}+2 \mathrm{COO}^{-} \rightleftarrows \text { crosslink }
\end{aligned}
$$

where the crosslink complex is shown in Fig.13.

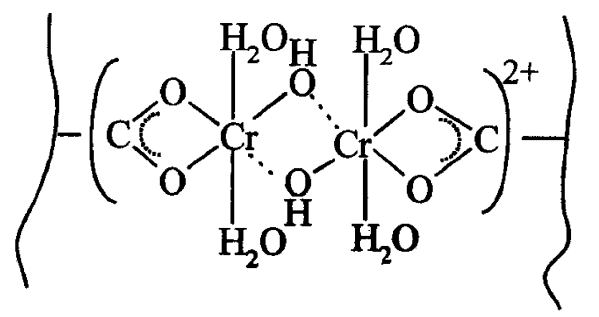

Figure 13. Crosslink structure of the dimeric chromium complex with carboxylic acid groups in partly hydrolysed poly(acrylamide) (HPAAM). 


\section{h) Side-chain liquid crystalline polymers}

The intermolecular attractive and repulsive forces operating in side-chain polymers are due to the interplay between various types of non-covalent interactions. The forces and dynamics associated with these subtle interactions can be investigated more closely by studying the behaviour of side-chain polymers in solution.

A series of discotic side chain polymers, as shown in Fig.14, were prepared by Kouwer in our laboratory [63, 64]. Solutions were prepared in 1,1,2-trichloroethane and the dynamic moduli were measured as a function of angular frequency. The storage modulus shows a rubber plateau at approximately $10 \mathrm{~N} / \mathrm{m}^{2}$ only, over at least five frequency decades $[65,66]$. Hence it follows that a very fragile rubber-like network is present. This fragility also follows from dynamic sweep experiments, from which it appears that the linear viscoelastic region is present at shear amplitudes of less than 0.02 .

The loss modulus increases with decreasing frequency, so that at still lower frequencies a maximum will be present, accompanied by a decrease of the storage modulus due to relaxation. Accordingly the network is not a permanent network, but a temporary one, just as has been shown above for SIS triblock copolymer solutions, aqueous gelatin solutions and aqueous PVA-borax solutions. The lifetime of the crosslinks in the present system appears to be more than $1000 \mathrm{~s}$.

A schematic representation of crosslinks with functionality 4 is shown in Fig.15. Of course functionality can vary from 4 to 8 for the three cases shown. One could wonder how many discs are really present in a crosslink. In order to calculate this number use has been made of a relationship for the average stacking number of discs, $<\mathrm{L}>$, that
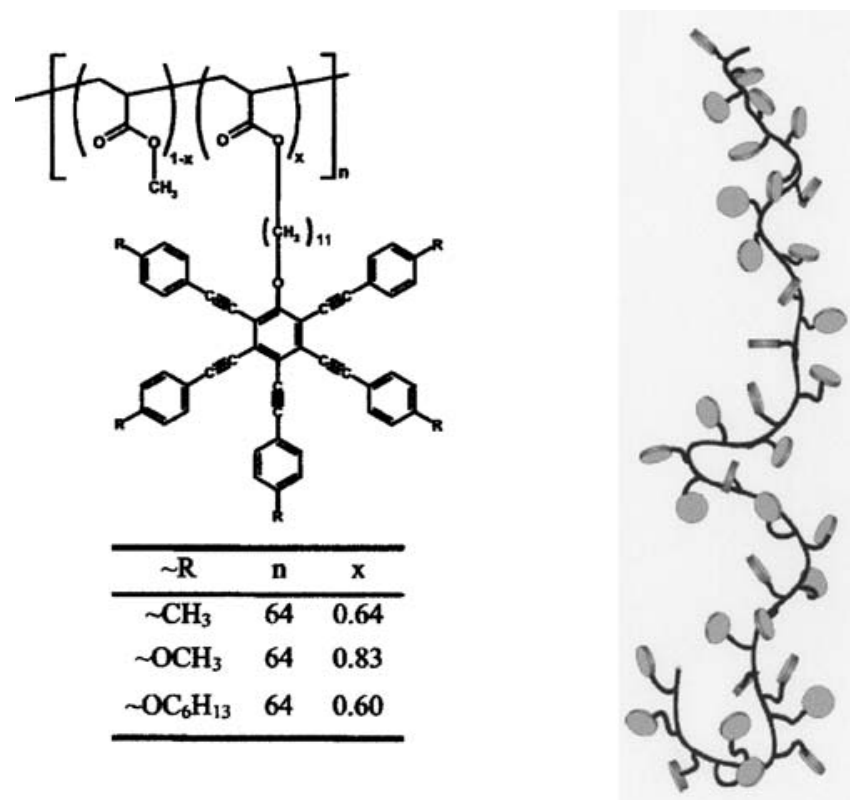

Figure 14. Left: Chemical structure of the discotic side-chain polymers. Right: Schematic representation of the discotic side-chain polymers. Reproduced from Macromolecules [Ref.68] by the courtesy of The American Chemical Society. 


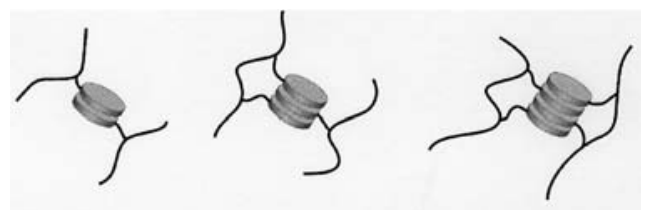

Figure 15. Schematic representation of various crosslinks with crosslink functionality 4 , with number of discs, $\mathrm{L}=2,3$, and 4. Reproduced from Macromolecules [Ref.68] by the courtesy of The American Chemical Society.

was used by Cates and Candau to calculate an average chain length of wormlike micelles in surfactant solutions [67]. The Cates Candau method was developed for long stacks (i.e. in our case for many discs in a column), whereas in the present case this number is presumably very small. Consequently the integral was replaced by a summation $[65,68]$. Results of calculations are presented in Table 2. It follows that the majority of the discs are in the free-state. For every system about a quarter of the number of discs belongs to a complex of two discs and a small fraction of discs is incorporated into stacks of three or more discs. The conclusion is that the average functionality of the crosslinks in these gels will be slightly above 4 .

Table 2. Fractions of stacked discs in $9 \%$ solutions in 1,1,2-dichloroethane for various kinds of R from Fig.14.

\begin{tabular}{cccc}
\hline $\mathrm{L}$ & $-\mathrm{CH}_{3}$ & $-\mathrm{OCH}_{3}$ & $-\mathrm{C}_{6} \mathrm{H}_{13}$ \\
\hline 1 & 0.51 & 0.71 & 0.61 \\
2 & 0.25 & 0.20 & 0.24 \\
3 & 0.12 & 0.06 & 0.09 \\
4 & 0.06 & 0.02 & 0.04 \\
5 & 0.03 & & 0.02 \\
\hline
\end{tabular}

The formation enthalpy, $\Delta H_{\mathrm{c}}$, of a crosslink can be calculated from the temperature dependence of the plateau value of the storage modulus [65, 68]. Results are given in Table 3. It appears that the crosslinking enthalpy is very low for all three polymers. In comparison, the formation enthalpy of a hydrogen bridge is on average $-11.4 \mathrm{~kJ} / \mathrm{mol}$.

Table 3. Crosslink formation enthalpies in $9 \%$ solutions in 1,1,2-dichloroethane for various kinds of R from Fig. 14.

\begin{tabular}{ll}
\hline$-\mathrm{R}$ & $\Delta H(\mathrm{~kJ} / \mathrm{mol})$ \\
\hline$-\mathrm{CH}_{3}$ & $-4.1 \pm 0.5$ \\
$-\mathrm{OCH}_{3}$ & $-1.4 \pm 0.3$ \\
$-\mathrm{C}_{6} \mathrm{H}_{13}$ & $-2.6 \pm 0.3$ \\
\hline
\end{tabular}

\section{Conclusions}

Although this review cannot be profuse, the main conclusion might be that there are as many kinds of crosslinks as there are thermoreversible gels. This makes the study of thermoreversible gels very exciting. Determination of viscoelastic properties is very 
important in this respect, but almost always also other techniques, theoretical as well as experimental, are needed to elucidate the nature of the crosslinks.

\section{References}

1. Flory PJ (1974) Discuss Faraday Soc 57: 1

2. Clark AH, Ross-Murphy SB (1987) Adv Polym Sci 83: 57

3. Guenet J-M (1992) Thermoreversible gelation of polymers and biopolymers, Academic Press, London

4. Te Nijenhuis K (1997) Adv Polym Sci 130: 1

5. Te Nijenhuis K (1990) In: Burchard W, Ross-Murphy SB (Eds) Physical Networks, Elsevier, London, Ch.2

6. Te Nijenhuis K, Dijkstra HJ (1975) Rheol Acta 14: 71

7. Te Nijenhuis K (1979) Doctoral Thesis, Delft, The Netherlands

8. Te Nijenhuis K, Winter HH (1989) Macromolecules 22: 411

9. Aiken W, Alfrey T, Janssen A, Mark H (1947) J Polym Sci 2: 178

10. Alfrey T, Wiederhorn N, Stein R, Tobolsky AV (1949) Ind Eng Chem 41: 107

11. Alfrey T, Wiederhorn N, Stein R, Tobolsky AV (1949) J Colloid Sci 4: 211

12. Hellwege KH, Johnsen U, Kockott D (1964) Kolloid Z u Z Polymere 194: 5

13. Juijn J, Gisolf JH, De Jong WA (1969) Kolloid Z u Z Polymere 235: 1157

14. Juijn J, Gisolf JH, De Jong WA (1973) Kolloid Z u Z Polymere 251: 456

15. Juijn J (1972) Doctoral Thesis, Delft, The Netherlands

16. Dorrestijn A, Keijzers AEM, Te Nijenhuis K (1981) Polymer 22: 305

17. Te Nijenhuis K (1991) Makromol Chem Macromol Symp 45: 117

18. Te Nijenhuis K (1996) Polym Gels Networks 4: 415

19. Clark J, Wellinghoff ST, Miller WG (1983) Polymer Prep Am Chem Soc, Div Polym Chem 24(2): 86

20. Berghmans H (1988) In: Kleintjens LA, Lemstra PJ (eds) Integration of fundamental polymer science and technology, Elsevier, London, Vol.2, p 296

21. Arnauts J, Berghmans H (1987) Polym Commun 28: 66

22. Arnauts J, Berghmans H (1990) In: Burchard W, Ross-Murphy SB (eds) Physical Networks, Elsevier, London, Ch.3

23. Van den Broecke PH, Berghmans H (1990) Makromol Chem, Macromol Symp 39: 59

24. Vandeweert P, Berghmans H, Tervoort Y (1991) Macromolecules 24: 3547

25. Callister S, Keller A, Hikmet RM (1990) Makromol Chem, Macromol Symp 39: 19

26. Raspaud ED, Lairez D, Adam M, Carton J-P (1994) Macromolecules 27: 2956

27. Mortensen K, Brown W, Jørgensen EB (1994) Macromolecules 27: 5654

28. Spitteler PHJ (1994) Doctoral Thesis. Twente University, The Netherlands

29. Vorenkamp EJ, Bosscher F, Challa G (1979) Polymer 20: 59

30. Schomaker E (1988) Doctoral Thesis, Groningen, The Netherlands

31. Burchard W, Pyrlik M, Rehage G (1971) Makromol Chem 145: 169

32. Pyrlik M, Borchard W, Rehage G, Uerpmann EP (1972) Angew Makromol Chem 36: 133

33. Pyrlik M, Rehage G (1975) Rheol Acta 14: 303

34. Pyrlik M, Rehage G (1976) Colloid Polym Sci 254: 329

35. Könnecke K, Rehage G (1981) Colloid Polym Sci 259: 1062

36. Könnecke K, Rehage G (1883) Makromol Chem 184: 2679

37. Ten Brinke G, Schomaker E, Challa G (1985) Macromolecules 18: 1925

38. Schomaker E, Ten Brinke G, Challa G (1985) Macromolecules 18: 1930

39. Kusuyama H, Takase M, Higashihata Y, Tseng HT, Chatani Y, Tadokoro H (1982) Polymer 23: 1256

40. Spěváček J, Schneider B (1983) Polymer 24: 971

41. Bosscher F, Ten Brinke G, Challa G (1982) Macromolecules 15: 1442

42. Veis A The Macromolecular Chemistry of Gelatin, Academic Press, New York (1964) 
43. Ramshaw JAM, Brodsky B (2003) in Aalbersberg WY, Hamer RJ, Jasperse P, De Jong HHJ, De Kruijf CG, Walstra P, De Wolf FA, (eds) Industrial Proteins in Perspective; Progress in Biotechnology, Volume 23, Ch V.2.1

44. Te Nijenhuis K (1981) Colloid Polym Sci 259:522

45. Kramer O (1992) private communication

46. Higgs PG, Ross-Murphy SB (1990) Int J Biol Macromol 12: 233

47. Ross-Murphy SB (1992) Polymer 33; 2622

48. Gilsenan PM, Ross-Murphy SB (2000) Food Hydrocolloids 14: 191

49. Te Nijenhuis, K. (2003) ) in Aalbersberg WY, Hamer RJ, Jasperse P, De Jong HHJ, De Kruijf CG, Walstra P, De Wolf FA, (eds) Industrial Proteins in Perspective; Progress in Biotechnology, Volume 23, Ch V.4.3

50. Shibayama M, Ikkai F, Moriwaki R, Nomura S (1994) Macromolecules 27: 1738

51. Beltman H, Doctoral Thesis Wageningen, The Netherlands

52. Beltman H, Lyklema J (1974) Discuss Faraday Chem Soc 57: 92

53. Pezron E, Leibler L, Ricard A, Audebert R (1985) Macromolecules 21: 1126

54. Deuel H, Neukom H (1949) Makromol Chem 3: 13

55. Ahad E (1974) J Appl Polym Sci 18: 1587

56. Saito S, Okuyama H, Kishimoto H, Fujiyama Y (1955) Kolloid Z 144: 41

57. Shibayama M, Yoshizawa H, Kurokawa H, Fujiwara H, Nomura S (1988) Polymer 29: 2066

58. Cheng ATY, Rodrigues R (1981) J Appl Polym Sci 26: 3895

59. Schultz RK, Myers RR (1969) Macromolecules 2: 281

60. Koike A, Nemoto N, Inoue T, Osaki K (1995) Macromolecules 28: 2339

61. Te Nijenhuis K, Mensert A, Zitha PLJ (2003) Rheol Acta 42: 132

62. Te Nijenhuis K (2002) Macromol Symp 171: 189

63. Kouwer PHJ (2002) Doctoral Thesis, Delft, The Netherlands

64. Kouwer PHJ, Jager WF, Mijs WJ (2000) Macromolecules 33: 4336

65. Franse MWCP (2003) Doctoral Thesis, Delft, The Netherlands

66. Franse MWCP, Te Nijenhuis K, Picken SJ (2003) Rheol Acta 42: 443

67. Cates ME, Candau SJ (1990) J Phys: Condens Matter 2: 6869

68. Franse MWCP, Te Nijenhuis K, Groenewold J, Picken SJ (2004) Macromolecules 37: 7839 